\title{
Prior SARS-CoV-2 infection rescues B and T cell responses to variants after first vaccine dose
}

\author{
Catherine J. Reynolds' ${ }^{1}$, Corinna Pade ${ }^{2} \uparrow$, Joseph M. Gibbons ${ }^{2} \uparrow$, David K. Butler ${ }^{1}$, Ashley D. Otter ${ }^{3}$, Katia \\ Menacho $^{4}$, Marianna Fontana ${ }^{5,6}$, Angelique Smit ${ }^{5}$, Jane E. Sackville-West', Teresa Cutino-Moguel ${ }^{4}$, Mala K. \\ Maini $^{8}$, Benjamin Chain ${ }^{8}$, Mahdad Noursadeghi ${ }^{8}$, UK COVIDsortium Immune Correlates Network屯, Tim \\ Brooks $^{3}$, Amanda Semper ${ }^{3}$, Charlotte Manisty ${ }^{4,9}$, Thomas A. Treibel ${ }^{4,9}$, James C. Moon ${ }^{4,9}$, UK COVIDsortium \\ Investigators $\ddagger$, Ana M. Valdes ${ }^{10,11}$, Áine McKnight ${ }^{2} \S$, Daniel M. Altmann ${ }^{12} \S$, Rosemary Boyton ${ }^{1,13} \S^{*}$
}

\begin{abstract}
${ }^{1}$ Department of Infectious Disease, Imperial College London, London, UK. ${ }^{2}$ Blizard Institute, Barts and the London School of Medicine and Dentistry, Queen Mary University of London, London, UK. ${ }^{3}$ National Infection Service, Public Health England, Porton Down, UK. ${ }^{4}$ St Bartholomew's Hospital, Barts Health NHS Trust, London, UK. ${ }^{5}$ Royal Free

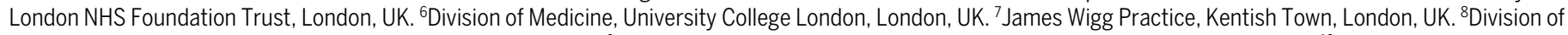
Infection and Immunity, University College London, London, UK. ${ }^{9}$ Institute of Cardiovascular Science, University College London, London, UK. ${ }^{10}$ Academic Rheumatology, Clinical Sciences, Nottingham City Hospital, Nottingham, UK. ${ }^{11} \mathrm{NIHR}$ Nottingham Biomedical Research Centre, Nottingham University Hospitals NHS Trust and University of Nottingham, Nottingham, UK. ${ }^{12}$ Department of Immunology and Inflammation, Imperial College London, London, UK. ${ }^{13}$ Lung Division, Royal Brompton and Harefield Hospitals, London, UK.

${ }^{*}$ Corresponding author: Email: r.boyton@imperial.ac.uk
\end{abstract}

†These authors contributed equally to this work.

$\S$ These authors contributed equally to this work.

fUK COVIDsortium Investigators and UK COVIDsortium Immune Correlates Network collaborators and affiliations are listed in the supplementary materials.

SARS-CoV-2 vaccine rollout has coincided with the spread of variants of concern. We investigated if single dose vaccination, with or without prior infection, confers cross protective immunity to variants. We analyzed $T$ and $B$ cell responses after first dose vaccination with the Pfizer/BioNTech mRNA vaccine BNT162b2 in healthcare workers (HCW) followed longitudinally, with or without prior Wuhan-Hu-1 SARSCoV-2 infection. After one dose, individuals with prior infection showed enhanced T cell immunity, antibody secreting memory B cell response to spike and neutralizing antibodies effective against B.1.1.7 and B.1.351. By comparison, HCW receiving one vaccine dose without prior infection showed reduced immunity against variants. B.1.1.7 and B.1.351 spike mutations resulted in increased, abrogated or unchanged T cell responses depending on human leukocyte antigen (HLA) polymorphisms. Single dose vaccination with BNT162b2 in the context of prior infection with a heterologous variant substantially enhances neutralizing antibody responses against variants.

During worldwide rollout of SARS-CoV-2 vaccines it is vital to understand how vaccination influences immune responses and protection among those who have had prior natural SARS-CoV-2 infection. This is a knowledge-gap since a history of previous infection was an exclusion criterion in Phase III vaccine trials (1). Countries have adopted diverse approaches, including the UK policy to maximize deployment of first doses to the largest possible numbers by extending the time interval to second dose. At the end of 2020, it became apparent several virus variants had emerged $(2,3)$ and that these might impact vaccine rollout. The B.1.1.7 variant, possessing the spike N501Y mutation, first emerged in the UK in December 2020 and spread rapidly (4). Additional variants of concern (VOC) include the B.1.351 variant, which emerged at about the same time in South Africa and the P.1 variant that emerged in January 2021 in Brazil. Both have the N501Y mutation, in addition to E484K, the latter implicated in escape from neutralizing antibody $(\mathrm{nAb})(5,6)$.

The Pfizer/BioNTech mRNA vaccine BNT162b2 encodes a prefusion stabilized, membrane-anchored SARS-CoV-2 fulllength spike protein modified by two proline substitutions ( 1 , $7,8)$. A two-dose regimen of $30 \mu \mathrm{g}$ BNT162b2, 21d apart, confers 95\% protection against Wuhan-Hu-1 SARS-CoV-2 (1), eliciting high $\mathrm{nAb}$ titers, as well as $\mathrm{CD} 4$ cell and $\mathrm{CD} 8$ responses (8). When given as a single $60 \mu \mathrm{g}$ dose, BNT162b1 induced virus $\mathrm{Ab}$ neutralization, but $\mathrm{T}$ cell responses were reduced compared with the standard prime-boost regime (8). Single $30 \mu \mathrm{g}$ dose, BNT162b1 was not reported beyond $\mathrm{d} 21$. However, the cumulative incidence of COVID-19 cases among 21,676 placebo and 21,699 vaccine recipients diverged 12 days after the first dose, indicating possible early-onset first dose protection (1). For those who were previously infected, single 
dose vaccination may act as a boost following natural infection. Therefore, we aimed to test the impact of prior SARSCoV-2 infection on $\mathrm{T}$ cell and $\mathrm{B}$ cell responses to first dose vaccination.

To do this, we analyzed $\mathrm{T}$ and $\mathrm{B}$ cell immunity after the first $30 \mu \mathrm{g}$ dose of the Pfizer/BioNTech mRNA vaccine BNT162b2, in a cohort of UK hospital healthcare workers (HCW) (9-12). The COVIDsortium HCW cohort has been studied longitudinally since the end of March 2020, providing accurate infection and immune history in the context of genotyping, including HLA imputation (10-12). Our aim was to compare $\mathrm{T}$ and $\mathrm{B}$ cell immunity after a first dose of vaccine in December 2020, in individuals post-infection (after natural infection), vaccinated post-infection (vaccination in the context of prior SARS-CoV-2 infection) and vaccinated naïve (single dose vaccination). We wished to explore if there is evidence for altered $\mathrm{T}$ cell recognition of the B.1.1.7 and B.1.351 variants, and in particular, of the N501Y mutation shared by several VOC.

The UK has deployed a heterodox vaccination regimen to maximize immune protection and slow spread of the B.1.1.7 lineage, giving an initial $30 \mu \mathrm{g}$ dose of BNT162b2, followed by boosting up to 12 weeks later (13). A cross-sectional sub-study $(\mathrm{n}=51)$ of the existing longitudinal HCW cohort (9-12) was recruited $22 \mathrm{~d}( \pm 2)$ after the first dose. After the start of the study, the majority of acute infections had already occurred among this cohort (11). At the time of receiving their first vaccine dose in December 2020, 25 individuals were approximately 39 weeks post SARS-CoV-2 infection with the Wuhan $\mathrm{Hu}-1$ strain and prior to the emergence of VOC and 26 were confirmed uninfected, having tested negative in longitudinal serology for spike and nucleocapsid (N) (table S1 and fig. S1).

We first measured SARS-CoV-2 $\mathrm{N}$ antibody longitudinally up to $16-18$ weeks, then at $28-30$ weeks and finally 42 weeks post-recruitment to confirm that there was no laboratory evidence of new infection at the time of drawing blood for the vaccine study at 42 weeks: none of the previously uninfected HCW had become seropositive (Fig. 1A). T cell responses to spike protein and MEP (mapped epitope peptides) in either post infection, vaccinated post infection or vaccinated naïve individuals were compared (Fig. 1B). Ninety six percent $(22 / 23)$ of vaccinated post infection individuals made a $\mathrm{T}$ cell response to spike protein compared to $70 \%(16 / 23)$ of vaccinated naïve individuals, with a 4-fold increase in magnitude of $\mathrm{T}$ cell response. Furthermore, while the $\mathrm{T}$ cell response to spike protein in vaccinated naïve individuals increased $(\mathrm{p}=$ 0.0440), it was lower than those of vaccinated post infection individuals ( $p=0.0557$ ) (Fig. 1C). As expected, there was no significant change in $\mathrm{T}$ cell response to $\mathrm{N}$ (a measure of immunity to natural infection) (fig. S2A).

Paired analysis of T cell immunity to spike protein in previously uninfected individuals, analyzed at the 16-18 week timepoint and 3 weeks after vaccination, showed a significantly increased response $(\mathrm{p}=0.0089)$ (Fig. 1D). Three individuals who previously showed a response, despite lack of laboratory evidence for infection (therefore presumably a cross-reactive response to an endemic human coronavirus) showed an unchanged or decreased response to spike after vaccination.

The size of the SARS-CoV-2 S1 specific memory B cell pool was investigated by B cell ELISpot (Fig. 1E and fig. S2B). As for $\mathrm{T}$ cell responses, the number of $\mathrm{S} 1$ specific $\mathrm{IgG}^{+}$antibody secreting cells (ASC) was far greater in vaccinated post infection individuals compared with vaccinated naïve individuals $(\mathrm{p}<0.0001)$. Prior infection generated a 63 -fold increase in S1 specific ASC. There were no pre-existing S1 specific ASC in uninfected HCW pre-vaccination. Twenty of 22 vaccinated naïve individuals had detectable S1 specific ASC comprising $0.02 \%$ to $1.54 \%$ of the memory B cell (MBC) pool. By comparison, all vaccinated post infection individuals had detectable S1 specific ASCs (1.90-50\% of MBC pool). We previously reported (14), spike receptor binding domain (RBD) enhanced $\mathrm{Ab}$ responses in the vaccinated post infection group. In this work, the vaccination naïve group attained similar antibody titers to the post infection group at 16-18 and 28-30 weeks (Fig. 1F). Vaccinated naïve individuals made a lower nAb response to WT virus than seen following natural infection at 16-18 weeks although this did not achieve statistical significance. In line with the findings for $\mathrm{MBC}$ and RBD binding, there was a significantly enhanced $n A b$ response in vaccinated post infection individuals compared with the vaccinated naïve group (Fig. 1G), the mean value being 25,273 compared to 420 , that is, a 60 -fold increase. To put this in context, these values are 43-fold higher than the values recorded after 2 vaccine doses in the Phase 1 trial (7). There was no correlation between the magnitude of the spike protein $\mathrm{T}$ cell response and the percentage of S1 specific ASC (Fig. 1H). As expected, there was a positive correlation between the percentage of S1 specific ASC and the serum titer of RBD antibody in the vaccinated post infection individuals $(r=0.6502$; $\mathrm{p}=0.0008$ ) (Fig. 1I). After vaccination, two previously infected individuals showed lower percentages of S1 specific memory B cells and reduced serum RBD specific antibody levels than the rest of the group; prior infection involving case-definition symptoms tended to be associated with a higher specific B cell frequency than milder disease (Fig. 1F and fig. S2C). These individuals who, despite infection, had also not shown a detectable $\mathrm{T}$ cell response (one never seroconverted and the other rapidly became seronegative during longitudinal follow up) had a poor or absent response to infection that was only minimally overcome by vaccination.

The data in Fig. 1 indicate that there is a strong primeboosting effect of prior infection on single dose vaccination. Augmentation is seen more strongly in MBC frequency, anti- 
$\mathrm{RBD}$, and $\mathrm{nAb}$ responses than for $\mathrm{T}$ cell response frequency. Furthermore, there was no correlation between S1 ASC frequency and $\mathrm{T}$ cell response frequency (Fig. $1 \mathrm{H})$. There is, however, a correlation between S1 ASC and RBD antibody titers, indicating that individuals with higher numbers of $\mathrm{MBC}$ make higher antibody responses, and individuals who had experienced infection clustered at the higher end of this response (Fig. 1I).

Shortly before the vaccination program was initiated, several VOC emerged, including the B.1.1.7 VOC. This variant has nine mutations in the spike protein. Several studies have reported weaker $\mathrm{nAb}$ responses to B.1.1.7 relative to the previously circulating Wuhan-Hu-1 strain $(2-6,15-18)$. The majority of SARS-CoV-2 immune naïve individuals made no $\mathrm{nAb}$ response to the B.1.1.7 (18/20) and B.1.351 (17/20) variants after single dose vaccination. In contrast, almost all vaccinated post infection individuals made a strong $\mathrm{nAb}$ response to the B.1.1.7 (24/24) and B.1.351 (23/24) variants after a single dose vaccination with a 46 -fold (B.1.1.7) and 63fold (B.1.351) increase in mean nAb IC50 in vaccinated post infection compared to vaccinated naïve individuals. In a paired analysis, we observed in vitro significantly reduced $\mathrm{nAb}$ potency to authentic B.1.1.7 variant virus ( $>24.7$-fold lower than response to Wuhan $\mathrm{Hu}-1, \mathrm{p}<0.0001$ ) in sera from individuals with a past medical history of natural infection (Fig. 2B). Worryingly, after single dose vaccination, 90\% $(18 / 20)$ of vaccinated naïve individuals showed no detectable nAbs (IC50 < 50) against B.1.1.7 (mean IC50 37, range 0 to 184; $\mathrm{p}=0.2090$ ), but did show demonstrable $\mathrm{nAb}$ responses to Wuhan $\mathrm{Hu}-1$ SARS-CoV-2 virus (mean IC50 420, range 80 to 2,$004 ; \mathrm{p}=0.0046$ ). In contrast, all vaccinated post infection individuals responded to single dose vaccination with substantially enhanced $\mathrm{nAb}$ responses, neutralizing not just Wuhan Hu-1 SARS-CoV-2 (mean IC50 25,273; range IC50 581 to 76,369), but also the B.1.1.7 (mean IC50 1717; range: IC50 52 to 4919) and B.1.351 (mean IC50 5451; range: IC50 41 to 20,411) variants (Fig. 2, A and B, and fig. S3). We show a 14.7fold reduction in neutralization (IC50) responses in SARSCoV-2 B.1.1.7 variant compared to Wuhan $\mathrm{Hu}-1$ virus in vaccinated post infection individuals. However, despite this fall the majority (22/24) remain within a "protective threshold." This was not the case for vaccinated naïve individuals. There was a 11.4-fold reduction in neutralization (IC50) responses against SARS-CoV-2 B.1.1.7 variant (mean, 37) compared to Wuhan Hu-1 virus (mean, 420) resulting in the majority of individuals (19/20) falling below the "protective threshold." This result was mirrored in the SARS-CoV-2 S1 specific memory B cell pool where reduced numbers of S1 specific $\mathrm{IgG}^{+} \mathrm{ASC}$ are seen (in vaccinated naïve individuals compared to vaccinated post infection individuals) responding to $\mathrm{S} 1$ antigen containing the N501Y, K417N and E484K mutations. Prior infection substantially enhances the specific memory B cell pool after single dose vaccination (Fig. 2C). We looked at correlations between RBD binding antibodies, B cell responses, $\mathrm{T}$ cell responses and IC50, comparing neutralization of Wuhan Hu-1, B.1.1.7 and B.1.315 live virus (Fig. 2D). Despite the lower neutralization of B.1.1.7 and B.1.315 variants, the pattern was retained of strong correlation between RBD antibody titer. S1 specific B cell frequency and neutralization and somewhat weaker correlation between $\mathrm{T}$ cell response and neutralization.

A lack of Ab-mediated protection in single-dose vaccinees could be mitigated by a broader repertoire of $\mathrm{T}$ cell responses (18). To investigate differences in T cell recognition, we designed peptide pools covering the affected regions of Wuhan$\mathrm{Hu}-1$, B.1.1.7, and B.1.351 variant sequence (table S2). We compared $\mathrm{T}$ cell responses to these peptide pools in PBMC from individuals vaccinated post infection and vaccinated naïve (Fig. 2E). Responses in post infection vaccinees were in general higher than in the vaccinated naïve individuals: note an enhanced response to the B.1.1.7 peptide pool. T cell responses were heterogeneous; responses to variant pools could be either higher or lower than to Wuhan Hu-1 pools. Alterations in affinity for the $\mathrm{T}$ cell receptor can lead to altered peptide ligand effects and differential polarization of cytokine effector programs, as we have previously observed in Zika virus infection (19). We wondered if this was also occurring for SARS-CoV-2; however, we found no evidence for immune deviation to interleukins (IL)-4, $-5,-10,-13,17 \mathrm{~A}$ or 23 (fig. S3).

For B.1.1.7 and B.1.351, attention has centered on the N501Y mutation, as this is implicated in altered ACE2 binding and enhanced infectivity and transmission but is also a target for $\mathrm{B}$ and $\mathrm{T}$ cell recognition. We initially looked at $\mathrm{T}$ cell responses following natural infection and found that at 16-18 weeks post infection, the N501Y mutation appeared to have no substantial differential impact on the $\mathrm{T}$ cell response (Fig. 2F), unlike $\mathrm{nAb}$ recognition (5).

The specific impact of any $\mathrm{T}$ cell epitope changes on the immune response against VOC depends on changes in peptide binding to the peptide-presenting HLA molecules. Since the HLA complex is the most polymorphic part of the human genome, any alteration to core HLA binding motifs will differentially impact people with some HLA alleles over others. We performed in silico analysis (NetMHCIIpan) to predict which of the B.1.1.7 and B.1.351 mutations were found in HLA core binding motifs and how this might impact binding to common HLAII alleles (DRB1*0101, DRB1*0301, DRB1*0401, DRB1*0701, DRB1*1101, DRB1*1301, and DRB1*1501) (tables S3 and S4). Some of the mutations did not fall in a region predicted to bind the HLAII alleles tested (D3L, T716I, T1001I, A1708D and 3675-7 SGF del). Although several mutations were not predicted to significantly change affinity for the HLAII alleles, others did show predicted differential 
affinities depending on host HLAII type (tables S3 and S4). Analyzing altered responses to the D1118H mutation, we noted that individuals who carried $\mathrm{DRB1}{ }^{\star} 0301$ and $\mathrm{DRB1}^{*} 0401$ showed enhanced $\mathrm{T}$ cell responses to the Wuhan Hu-1 peptide compared to those that did not $(p=0.0072)$ (Fig. $2 \mathrm{G})$. T cell responses to the variant peptide appeared to be reduced in individuals carrying $\mathrm{DRB1}{ }^{*} 0301$ and $\mathrm{DRB1}{ }^{*} 0401$ (Fig. 2H). There is a basis for this in terms of differential HLAII binding as the $\mathrm{D}$ to $\mathrm{H}$ mutation is predicted to lose the $\mathrm{T}$ cell epitope for people carrying $\mathrm{DRB1}{ }^{*} 0301$ and $\mathrm{DRB1}{ }^{*} 0401$, but not for example in those who are $\mathrm{DRB1}^{*} 0701$ or DRB1*1501 who would be predicted to show an enhanced response (table S3). People who are DRB1* 1301 are predicted to gain a response as a consequence of this mutation. Analyzing responses to the E484K mutation seen in B.1.351 and P.1 variants, we noted that it did not fall in a region predicted to bind the HLAII alleles tested (table S4). The mutation appeared to have no substantial or differential impact on T cell responses (Fig. 2I).

When we primed transgenic mice expressing human HLA-DRB1*0401 with the Wuhan Hu-1 peptide pool, T cell responses to the B.1.1.7 variant peptide pool were significantly reduced $(\mathrm{p}=0.0286)$ (Fig. $2 \mathrm{~J})$. Furthermore, the $\mathrm{T}$ cell response to the spike N501Y mutation common to all three of the current VOC was ablated.

In this HCW cohort, vaccinated naïve individuals made an anti S1 RBD Ab response with a mean titer of about $100 \mathrm{U} / \mathrm{ml}$ at $\mathrm{d} 22( \pm 2 \mathrm{~d})$ after vaccination, roughly equivalent to the mean peak $\mathrm{Ab}$ response after natural infection (14). However, the spike $\mathrm{T}$ cell response after one dose was lower than after natural infection, and for $30 \%$ of vaccinees no response could be measured. However, $\mathrm{T}$ cell responses are enhanced 4-fold in those vaccinated post-infection. This $\mathrm{T}$ cell enhancement is small relative to the 63-fold change in ASC and the corresponding 140-fold change in Roche anti-S (RBD) Ab levels we observed after one vaccine dose in $\mathrm{HCW}$ vaccinated post infection (14). While much has been written about the impact of rapidly waning serum antibody, our findings confirm MBC are nevertheless primed and able to contribute a rapid, large response to repeat exposure. The rather large effect on B cell priming and restimulation, relative to $\mathrm{T}$ cells, in previously infected single-dose vaccinated individuals may reflect the fact that, among the nuanced differences between the licensed COVID-19 vaccines, aspects of the mRNA adjuvant effect appear to skew immunity to high nAb titers, which may underpin its high efficacy. Our evidence for enhanced vaccine responses after infection supports the case that only one vaccine dose is necessary to maximize immune protection for SARS-CoV-2 experienced individuals $(14,20)$.

It is striking that the high IC50 titers in those vaccinated after infection provide such a large protective margin that responses to authentic B.1.1.7 and B.1.351variants are also high.
In contrast, $\mathrm{nAb}$ responses in individuals several months on from mild infection show much lower IC50s against B.1.1.7 and B.1.351, often <100. Similarly, the majority of responses in naïve individuals after one dose show weak recognition of B.1.1.7 and B.1.351. This finding indicates potentially poor protection against B.1.1.7 and B.1.351 in individuals who have experienced natural infection or who have only had one vaccine dose.

It is important to map the effect of VOC mutations on any evasion of $\mathrm{T}$ cell immunity. The case has been made that reductions in antibody neutralization of mutant spike may be mitigated by protective $\mathrm{T}$ cells (8). A case has been made for the role of $\mathrm{T}$ cells as correlates of protection (21). Our evidence from this analysis $22 \mathrm{~d}( \pm 2)$ after one dose is that $\mathrm{T}$ cell immunity is mostly variably low but also relatively unperturbed by the N501Y mutation. The other mutations we considered that overlay CD4 epitopes were, as might be predicted, distributed across the range of HLAII polymorphisms. Those alleles associated with loss of CD4 response to the variant pool tended to be those with a lysine in pocket 4 of the groove (HLA-DR residue 71 $\beta$ ), while those with an increased response to the variant pool tend to be those with a smaller, alanine. In HLA-DRB1*0401 transgenics we confirmed that in the context of a given HLAII heterodimer, the N501Y mutation can result in ablation of this part of the $T$ cell response, demonstrating that HLA polymorphisms are likely to be significant determinants of responder/nonresponder status with respect to vaccine escape.

SARS-CoV-2 immunity now encompasses post infection plus either zero, one or two vaccine doses and first and second dose naïve vaccinated. Single dose vaccination post infection achieves similar levels of S1 RBD binding antibodies to two doses in naïve vaccinated individuals and second dose vaccination in one dose vaccinated post infection individuals offers no additional enhancement (22). Moving forward, it will be important to resolve the quantitative and qualitative differences between these groups in terms of neutralizing antibody repertoire as well as phenotype and durability of memory B and T cell responses. Durability of immunity to natural infection and following vaccination, as well as sustained vaccine efficacy and vaccine escape need to be monitored over time.

\section{REFERENCES AND NOTES}

1. F. P. Polack, S. J. Thomas, N. Kitchin, J. Absalon, A. Gurtman, S. Lockhart, J. L. Perez, G. Pérez Marc, E. D. Moreira, C. Zerbini, R. Bailey, K. A. Swanson, S. Roychoudhury, K. Koury, P. Li, W. V. Kalina, D. Cooper, R. W. Frenck Jr., L. L. Hammitt, Ö. Türeci, H. Nell, A. Schaefer, S. Ünal, D. B. Tresnan, S. Mather, P. R. Dormitzer, U. Şahin, K. U. Jansen, W. C. Gruber; C4591001 Clinical Trial Group, Safety and efficacy of the BNT162b2 mRNA Covid-19 vaccine. N. Engl. J. Med. 383, 2603-2615 (2020). doi:10.1056/NEJMoa2034577 Medline

2. J. R. Mascola, B. S. Graham, A. S. Fauci, SARS-CoV-2 viral variants-tackling a moving target. JAMA 325, 1261-1262 (2021). doi:10.1001/jama.2021.2088 Medline 
3. D. M. Altmann, R. J. Boyton, R. Beale, Immunity to SARS-CoV-2 variants of concern. Science 371, 1103-1104 (2021). doi:10.1126/science.abg7404 Medline

4. A. Rambaut, N. Loman, O. Pybus, W. Barclay, J. Barrett, A. Carabelli, T. Connor, T. Peacock, D. L. Robertson, E. Volz, on behalf of COVID-19 Genomics Consortium UK, (CoG-UK), Preliminary genomic characterisation of an emergent SARS-CoV2 lineage in the UK defined by a novel set of spike mutations, virological.org (2020); https://virological.org/t/preliminary-genomic-characterisation-of-anemergent-sars-cov-2-lineage-in-the-uk-defined-by-a-novel-set-of-spikemutations/563.

5. Z. Wang, F. Schmidt, Y. Weisblum, F. Muecksch, C. O. Barnes, S. Finkin, D. SchaeferBabajew, M. Cipolla, C. Gaebler, J. A. Lieberman, T. Y. Oliveira, Z. Yang, M. E. Abernathy, K. E. Huey-Tubman, A. Hurley, M. Turroja, K. A. West, K. Gordon, K. G. Millard, V. Ramos, J. Da Silva, J. Xu, R. A. Colbert, R. Patel, J. Dizon, C. UnsonO'Brien, I. Shimeliovich, A. Gazumyan, M. Caskey, P. J. Bjorkman, R. Casellas, T. Hatziioannou, P. D. Bieniasz, M. C. Nussenzweig, mRNA vaccine-elicited antibodies to SARS-CoV-2 and circulating variants. Nature 592, 616-622 (2021). doi:10.1038/s41586-021-03324-6 Medline

6. D. A. Collier, A. De Marco, I. A. T. M. Ferreira, B. Meng, R. P. Datir, A. C. Walls, S. A. Kemp, J. Bassi, D. Pinto, C. Silacci-Fregni, S. Bianchi, M. A. Tortorici, J. Bowen, K. Culap, S. Jaconi, E. Cameroni, G. Snell, M. S. Pizzuto, A. F. Pellanda, C. Garzoni, A. Riva, A. Elmer, N. Kingston, B. Graves, L. E. McCoy, K. G. C. Smith, J. R. Bradley, N. Temperton, L. Ceron-Gutierrez, G. Barcenas-Morales, W. Harvey, H. W. Virgin, A. Lanzavecchia, L. Piccoli, R. Doffinger, M. Wills, D. Veesler, D. Corti, R. K. Gupta; CITIID-NIHR BioResource COVID-19 Collaboration; COVID-19 Genomics UK (COGUK) Consortium, Sensitivity of SARS-CoV-2 B.1.1.7 to mRNA vaccine-elicited antibodies. Nature 10.1038/s41586-021-03412-7 (2021). Medline

7. E. E. Walsh, R. W. Frenck Jr., A. R. Falsey, N. Kitchin, J. Absalon, A. Gurtman, S. Lockhart, K. Neuzil, M. J. Mulligan, R. Bailey, K. A. Swanson, P. Li, K. Koury, W. Kalina, D. Cooper, C. Fontes-Garfias, P. Y. Shi, Ö. Türeci, K. R. Tompkins, K. E. Lyke, V. Raabe, P. R. Dormitzer, K. U. Jansen, U. Şahin, W. C. Gruber, Safety and immunogenicity of two RNA-based Covid-19 vaccine candidates. N. Engl. J. Med. 383, 2439-2450 (2020). doi:10.1056/NEJMoa2027906 Medline

8. U. Sahin, A. Muik, E. Derhovanessian, I. Vogler, L. M. Kranz, M. Vormehr, A. Baum, K. Pascal, J. Quandt, D. Maurus, S. Brachtendorf, V. Lörks, J. Sikorski, R. Hilker, D. Becker, A. K. Eller, J. Grützner, C. Boesler, C. Rosenbaum, M. C. Kühnle, U. Luxemburger, A. Kemmer-Brück, D. Langer, M. Bexon, S. Bolte, K. Karikó, T. Palanche, B. Fischer, A. Schultz, P. Y. Shi, C. Fontes-Garfias, J. L. Perez, K. A. Swanson, J. Loschko, I. L. Scully, M. Cutler, W. Kalina, C. A. Kyratsous, D. Cooper, P. R. Dormitzer, K. U. Jansen, Ö. Türeci, COVID-19 vaccine BNT162b1 elicits human antibody and $T_{H} 1 \mathrm{~T}$ cell responses. Nature 586, 594-599 (2020). doi:10.1038/s41586-020-2814-7 Medline

9. T. A. Treibel, C. Manisty, M. Burton, Á. McKnight, J. Lambourne, J. B. Augusto, X Couto-Parada, T. Cutino-Moguel, M. Noursadeghi, J. C. Moon, COVID-19: PCR screening of asymptomatic health-care workers at London hospital. Lancet 395 , 1608-1610 (2020). doi:10.1016/S0140-6736(20)31100-4 Medline

10. J. B. Augusto, K. Menacho, M. Andiapen, R. Bowles, M. Burton, S. Welch, A. N. Bhuva, A. Seraphim, C. Pade, G. Joy, M. Jensen, R. H. Davies, G. Captur, M. Fontana, H. Montgomery, B. O'Brien, A. D. Hingorani, T. Cutino-Moguel, Á. McKnight, H. Abbass, M. Alfarih, Z. Alldis, G. L. Baca, A. Boulter, O. V. Bracken, N. Bullock, N. Champion, C. Chan, X. Couto-Parada, K. Dieobi-Anene, K. Feehan, G. Figtree, M. C. Figtree, M. Finlay, N. Forooghi, J. M. Gibbons, P. Griffiths, M. Hamblin, L. Howes, I. Itua, M. Jones, V. Jardim, V. Kapil, W.-Y. Jason Lee, V. Mandadapu, C. Mfuko, O. Mitchelmore, S. Palma, K. Patel, S. E. Petersen, B. Piniera, R. Raine, A. Rapala, A. Richards, G. Sambile, J. Couto de Sousa, M. Sugimoto, G. D. Thornton, J. Artico, D. Zahedi, R. Parker, M. Robathan, L. M. Hickling, N. Ntusi, A. Semper, T. Brooks, J. Jones, A. Tucker, J. Veerapen, M. Vijayakumar, T. Wodehouse, L. Wynne, T. A. Treibel, M. Noursadeghi, C. Manisty, J. C. Moon, Healthcare Workers Bioresource: Study outline and baseline characteristics of a prospective healthcare worker cohort to study immune protection and pathogenesis in COVID-19. Wellcome Open Res. 5, 179 (2020). doi:10.12688/wellcomeopenres.16051.2 Medline

11. C. J. Reynolds, L. Swadling, J. M. Gibbons, C. Pade, M. P. Jensen, M. O. Diniz, N. M. Schmidt, D. K. Butler, O. E. Amin, S. N. L. Bailey, S. M. Murray, F. P. Pieper, S. Taylor, J. Jones, M. Jones, W. J. Lee, J. Rosenheim, A. Chandran, G. Joy, C. Di Genova, N. Temperton, J. Lambourne, T. Cutino-Moguel, M. Andiapen, M.
Fontana, A. Smit, A. Semper, B. O'Brien, B. Chain, T. Brooks, C. Manisty, T. Treibel, J. C. Moon, M. Noursadeghi, D. M. Altmann, M. K. Maini, Á. McKnight, R. J. Boyton; COVIDsortium investigators; COVIDsortium immune correlates network, Discordant neutralizing antibody and T cell responses in asymptomatic and mild SARS-CoV-2 infection. Sci. Immunol. 5, eabf3698 (2020). doi:10.1126/sciimmunol.abf3698 Medline

12. C. Manisty, T. A. Treibel, M. Jensen, A. Semper, G. Joy, R. K. Gupta, T. CutinoMoguel, M. Andiapen, J. Jones, S. Taylor, A. Otter, C. Pade, J. Gibbons, J. Lee, J. Bacon, S. Thomas, C. Moon, M. Jones, D. Williams, J. Lambourne, M. Fontana, D. M. Altmann, R. Boyton, M. Maini, A. McKnight, B. Chain, M. Noursadeghi, J. C. Moon, Time series analysis and mechanistic modelling of heterogeneity and seroreversion in antibody responses to mild SARS-CoV-2 infection. EBioMedicine 65, 103259 (2021). doi:10.1016/j.ebiom.2021.103259 Medline

13. COVID-19 vaccines: Acting on the evidence. Nat. Med. 27, 183 (2021). doi:10.1038/s41591-021-01261-5 Medline

14. C. Manisty, A. D. Otter, T. A. Treibel, Á. McKnight, D. M. Altmann, T. Brooks, M. Noursadeghi, R. J. Boyton, A. Semper, J. C. Moon, Antibody response to first BNT162b2 dose in previously SARS-CoV-2-infected individuals. Lancet 397, 1057-1058 (2021). doi:10.1016/S0140-6736(21)00501-8 Medline

15. X. Shen, H. Tang, C. McDanal, K. Wagh, W. Fischer, J. Theiler, H. Yoon, D. Li, B. F. Haynes, K. O. Sanders, S. Gnanakaran, N. Hengartner, R. Pajon, G. Smith, G. M. Glenn, B. Korber, D. C. Montefiori, SARS-CoV-2 variant B.1.1.7 is susceptible to neutralizing antibodies elicited by ancestral spike vaccines. Cell Host Microbe 29 , 529-539.e3 (2021). doi:10.1016/j.chom.2021.03.002 Medline

16. A. J. Greaney, A. N. Loes, K. H. D. Crawford, T. N. Starr, K. D. Malone, H. Y. Chu, J. D. Bloom, Comprehensive mapping of mutations in the SARS-CoV-2 receptorbinding domain that affect recognition by polyclonal human plasma antibodies. Cell Host Microbe 29, 463-476.e6 (2021). doi:10.1016/i.chom.2021.02.003 Medline

17. P. Supasa, D. Zhou, W. Dejnirattisai, C. Liu, A. J. Mentzer, H. M. Ginn, Y. Zhao, H. M. E. Duyvesteyn, R. Nutalai, A. Tuekprakhon, B. Wang, G. C. Paesen, J. SlonCampos, C. López-Camacho, B. Hallis, N. Coombes, K. R. Bewley, S. Charlton, T. S. Walter, E. Barnes, S. J. Dunachie, D. Skelly, S. F. Lumley, N. Baker, I. Shaik, H. E. Humphries, K. Godwin, N. Gent, A. Sienkiewicz, C. Dold, R. Levin, T. Dong, A. J. Pollard, J. C. Knight, P. Klenerman, D. Crook, T. Lambe, E. Clutterbuck, S. Bibi, A. Flaxman, M. Bittaye, S. Belij-Rammerstorfer, S. Gilbert, D. R. Hall, M. A. Williams, N. G. Paterson, W. James, M. W. Carroll, E. E. Fry, J. Mongkolsapaya, J. Ren, D. I. Stuart, G. R. Screaton, Reduced neutralization of SARS-CoV-2 B.1.1.7 variant by convalescent and vaccine sera. Cell 184, 2201-2211.e7 (2021) doi:10.1016/i.cell.2021.02.033 Medline

18. A. Muik, A. K. Wallisch, B. Sänger, K. A. Swanson, J. Mühl, W. Chen, H. Cai, D. Maurus, R. Sarkar, Ö. Türeci, P. R. Dormitzer, U. Şahin, Neutralization of SARSCoV-2 lineage B.1.1.7 pseudovirus by BNT162b2 vaccine-elicited human sera. Science 371, 1152-1153 (2021). 10.1126/science.abg6105 Medline

19. C. J. Reynolds, O. M. Suleyman, A. M. Ortega-Prieto, J. K. Skelton, P. Bonnesoeur, A. Blohm, V. Carregaro, J. S. Silva, E. A. James, B. Maillère, M. Dorner, R. J. Boyton, D. M. Altmann, T cell immunity to Zika virus targets immunodominant epitopes that show cross-reactivity with other Flaviviruses. Sci. Rep. 8, 672 (2018). doi:10.1038/s41598-017-18781-1 Medline

20. F. Krammer, K. Srivastava, H. Alshammary, A. A. Amoako, M. H. Awawda, K. F. Beach, M. C. Bermúdez-González, D. A. Bielak, J. M. Carreño, R. L. Chernet, L. Q. Eaker, E. D. Ferreri, D. L. Floda, C. R. Gleason, J. Z. Hamburger, K. Jiang, G. Kleiner, D. Jurczyszak, J. C. Matthews, W. A. Mendez, I. Nabeel, L. C. F. Mulder, A. J. Raskin, K. T. Russo, A. T. Salimbangon, M. Saksena, A. S. Shin, G. Singh, L. A. Sominsky, D. Stadlbauer, A. Wajnberg, V. Simon, Antibody responses in seropositive persons after a single dose of SARS-CoV-2 mRNA vaccine. N. Engl. J. Med. 384, 1372-1374 (2021). doi:10.1056/NEJMc2101667 Medline

21. A. Bertoletti, A. T. Tan, N. Le Bert, The T-cell response to SARS-CoV-2: Kinetic and quantitative aspects and the case for their protective role. Oxford Open Immunology 2, iqab006 (2021). doi:10.1093/oxfimm/iqab006

22. R. R. Goel, S. A. Apostolidis, M. M. Painter, D. Mathew, A. Pattekar, O. Kuthuru, S. Gouma, P. Hicks, W. Meng, A. M. Rosenfeld, S. Dysinger, K. A. Lundgreen, L. KuriCervantes, S. Adamski, A. Hicks, S. Korte, D. A. Oldridge, A. E. Baxter, J. R. Giles, M. E. Weirick, C. M. McAllister, J. Dougherty, S. Long, K. D'Andrea, J. T. Hamilton, M. R. Betts, E. T. Luning Prak, P. Bates, S. E. Hensley, A. R. Greenplate, E. J. 
Wherry, Distinct antibody and memory B cell responses in SARS-CoV-2 naïve and recovered individuals following mRNA vaccination. Sci. Immunol. 6, eabi6950 (2021). doi:10.1126/sciimmunol.abi6950 Medline

23. Public Health England, COVID-19: laboratory evaluations of serological assays, gov.uk, 16 March 2021; www.gov.uk/government/publications/covid-19laboratory-evaluations-of-serological-assays.

24. Y. Peng, A. J. Mentzer, G. Liu, X. Yao, Z. Yin, D. Dong, W. Dejnirattisai, T. Rostron, P. Supasa, C. Liu, C. López-Camacho, J. Slon-Campos, Y. Zhao, D. I. Stuart, G. C. Paesen, J. M. Grimes, A. A. Antson, O. W. Bayfield, D. E. D. P. Hawkins, D. S. Ker, B. Wang, L. Turtle, K. Subramaniam, P. Thomson, P. Zhang, C. Dold, J. Ratcliff, P. Simmonds, T. de Silva, P. Sopp, D. Wellington, U. Rajapaksa, Y.-L. Chen, M. Salio, G. Napolitani, W. Paes, P. Borrow, B. M. Kessler, J. W. Fry, N. F. Schwabe, M. G. Semple, J. K. Baillie, S. C. Moore, P. J. M. Openshaw, M. A. Ansari, S. Dunachie, E. Barnes, J. Frater, G. Kerr, P. Goulder, T. Lockett, R. Levin, Y. Zhang, R. Jing, L.-P. Ho, R. J. Cornall, C. P. Conlon, P. Klenerman, G. R. Screaton, J. Mongkolsapaya, A. McMichael, J. C. Knight, G. Ogg, T. Dong; Oxford Immunology Network Covid-19 Response T cell Consortium; ISARIC4C Investigators, Broad and strong memory $\mathrm{CD}^{+}$and $\mathrm{CD}^{+} \mathrm{T}$ cells induced by SARS-CoV-2 in UK convalescent individuals following COVID-19. Nat. Immunol. 21, 1336-1345 (2020). doi:10.1038/s41590020-0782-6 Medline

25. GISAID, Tracking of variants; www.gisaid.org/hcov19-variants/.

26. B. Reynisson, B. Alvarez, S. Paul, B. Peters, M. Nielsen, NetMHCpan-4.1 and NetMHCllpan-4.0: Improved predictions of MHC antigen presentation by concurrent motif deconvolution and integration of MS MHC eluted ligand data. Nucleic Acids Res. 48, W449-W454 (2020). doi:10.1093/nar/gkaa379 Medline

27. K. J. Quigley, C. J. Reynolds, A. Goudet, E. J. Raynsford, R. Sergeant, A. Quigley, S. Worgall, D. Bilton, R. Wilson, M. R. Loebinger, B. Maillere, D. M. Altmann, R. J. Boyton, Chronic infection by mucoid Pseudomonas aeruginosa associated with dysregulation in T-cell immunity to outer membrane porin F. Am. J. Respir. Crit. Care Med. 191, 1250-1264 (2015). doi:10.1164/rccm.201411-19950C Medline

28. C. Reynolds, A. Goudet, K. Jenjaroen, M. Sumonwiriya, D. Rinchai, J. Musson, S. Overbeek, J. Makinde, K. Quigley, J. Manji, N. Spink, P. Yos, V. Wuthiekanun, G. Bancroft, J. Robinson, G. Lertmemongkolchai, S. Dunachie, B. Maillere, M. Holden, D. Altmann, R. Boyton, T cell immunity to the alkyl hydroperoxide reductase of Burkholderia pseudomallei: A correlate of disease outcome in acute melioidosis. J. Immunol. 194, 4814-4824 (2015). doi:10.4049/jimmunol.1402862 Medline

\section{ACKNOWLEDGMENTS}

The authors thank all the HCW participants for donating their samples and data for these analyses, and the research teams involved in consenting, recruitment and sampling of the HCW participants. The COVIDsortium Healthcare Workers bioresource was approved by the ethical committee of UK National Research Ethics Service (20/SC/0149) and registered on ClinicalTrials.gov (NCT04318314). The study conformed to the principles of the Helsinki Declaration, and all subjects gave written informed consent. The authors thank Stuart Astbury for help imputing HLA genotypes from GWAS data, Sam Murray, Franziska Pieper and Kai-Min Lin for help processing HCW PBMC and serum samples and the James Wigg Practice, London, UK for support. Funding: The COVIDsortium is supported by funding donated by individuals, charitable Trusts, and corporations including Goldman Sachs, Citadel and Citadel Securities, The Guy Foundation, GW Pharmaceuticals, Kusuma Trust, and Jagclif Charitable Trust, and enabled by Barts Charity with support from UCLH Charity. Wider support is acknowledged on the COVIDsortium website. Institutional support from Barts Health NHS Trust and Royal Free NHS Foundation Trust facilitated study processes, in partnership with University College London and Queen Mary University of London. R.J.B. and D.M.A. are supported by MRC (MR/S019553/1, MR/R02622X/1 and MR/V036939/1), NIHR Imperial Biomedical Research Centre (BRC):ITMAT, Cystic Fibrosis Trust SRC (2019SRC015), and Horizon 2020 Marie Skłodowska-Curie Innovative Training Network (ITN) European Training Network (No 860325). Á.M. is supported by Rosetrees Trust, The John Black Charitable Foundation, and Medical College of St Bartholomew's Hospital Trust. J.C.M., C.M. and T.A.T. are directly and indirectly supported by the University College London Hospitals (UCLH) and Barts NIHR Biomedical Research Centres and through the British Heart Foundation (BHF) Accelerator Award (AA/18/6/34223). T.A.T. is funded by a BHF Intermediate Research
Fellowship (FS/19/35/34374). M.N. is supported by the Wellcome Trust (207511/Z/17/Z) and by NIHR Biomedical Research Funding to UCL and UCLH. M.K.M. is supported by UKRI/NIHR UK-CIC, Wellcome Trust Investigator Award (214191/Z/18/Z) and CRUK Immunology grant (26603). A.M.V., Á.M., C.M. and J.C.M. were supported by the UKRI/MRC Covid-19 Rapid response grant COV0331 MR/V027883/1. The funders had no role in study design, data collection, data analysis, data interpretation, or writing of the report. Author contributions: R.J.B. conceptualized the study reported. C.M., T.A.T., J.C.M., M.N., A.M., D.M.A. and R.J.B. designed the study. R.J.B. and D.M.A. designed and supervised the T cell and B cell experiments. A.M.V. supervised HLA analysis. T.B. and A.Se. supervised S1 IgG and N IgG/lgM studies. Á.M. designed and supervised the nAb experiments. C.J.R. and D.K.B. developed, performed and analyzed the T cell and B cell experiments. J.M.G. and C.P. developed, performed and analyzed the nAb experiments. A.D.O. performed and A.Se. analyzed the RBD and $\mathrm{N}$ antibody assays. T.B., C.M., A.M., T.T., J.C.M., and M.N. conceptualized and established the HCW cohort. R.J.B., T.A.T., J.C.M., and C.M. designed the vaccine sub-study recruitment. K.M., M.F., A.S., J.S.W., C.M., T.A.T., and J.C.M. collected HCW samples. C.J.R. and D.K.B processed HCW samples. R.J.B., C.J.R., D.K.B., J.M.G., C.P., Á.M. and D.M.A. analyzed the data. D.M.A., C.J.R., M.K.M., Á.M., B.C., C.M., T.A.T., J.C.M., A.Se., T.B., M.N., A.M.V. and R.J.B. interpreted the data. R.J.B. and D.M.A. wrote the manuscript with input from all the authors. All the authors reviewed and edited the manuscript and figures. Competing interests: R.J.B. and D.M.A. are members of the Global $T$ cell Expert Consortium and have consulted for Oxford Immunotec outside the submitted work. Data and materials availability: All data needed to evaluate the conclusions in the paper are present in the paper or the supplementary materials. SARS-CoV-2 nucleoprotein (100982) and SARS-CoV-2 spike (100979) are available from Dr Peter Cherepanov, Francis Crick Institute, UK under a material transfer agreement with Centre for AIDS Reagents (CFAR), National Institute for Biological Standards and Control (NIBSC), UK. The SARSCoV-2 B.1.1.7 isolate was obtained from NIBSC, thanks to the contribution of PHE Porton Down and Dr Simon Funnell. The nCoV19 isolate/UK ex South African/2021 lineage B.1.351 EVA catalog code 04V-04071 was obtained from European Virus Archive Global, PHE Porton Down. The SARS-CoV-2 Wuhan Hu-1 Human 2019-nCoV Isolate EVA catalog code 026V-03883 was obtained from European Virus Archive Global, Charité - Universitätsmedizin Berlin. This work is licensed under a Creative Commons Attribution 4.0 International (CC BY 4.0) license, which permits unrestricted use, distribution, and reproduction in any medium, provided the original work is properly cited. To view a copy of this license, visit https://creativecommons.org/licenses/by/4.0/. This license does not apply to figures/photos/artwork or other content included in the article that is credited to a third party; obtain authorization from the rights holder before using such material.

\section{SUPPLEMENTARY MATERIALS}

science.sciencemag.org/cgi/content/full/science.abh1282/DC1

Materials and Methods

Figs. S1 to S4

Tables S1 to S5

UK COVIDsortium Investigators Collaborator List

UK COVIDsortium Immune Correlates Network Collaborator List

References (23-28)

MDAR Reproducibility Checklist

21 February 2021; accepted 26 April 2021

Published online 30 April 2021

10.1126/science.abh1282 
A

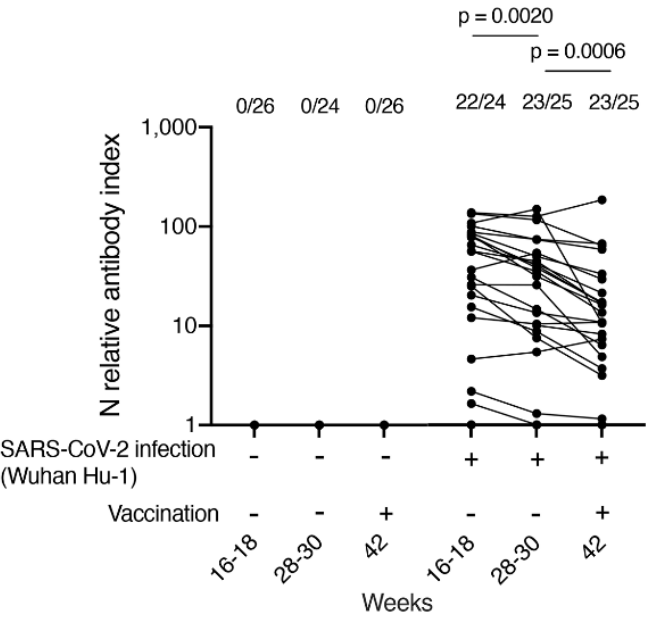

C

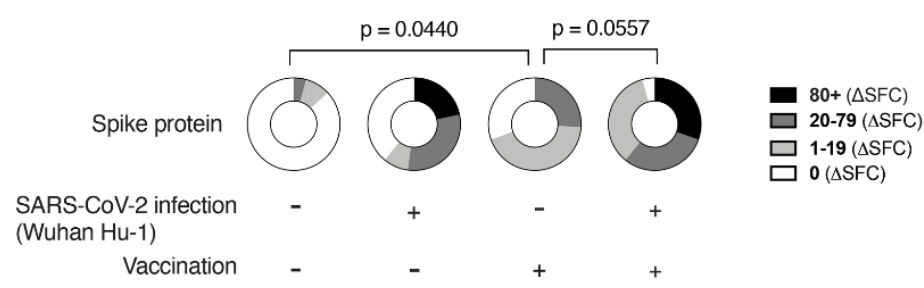

B

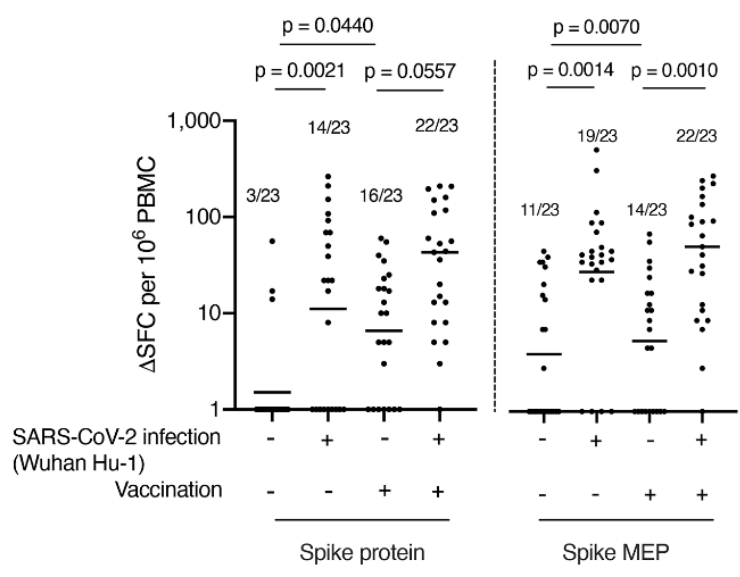

D

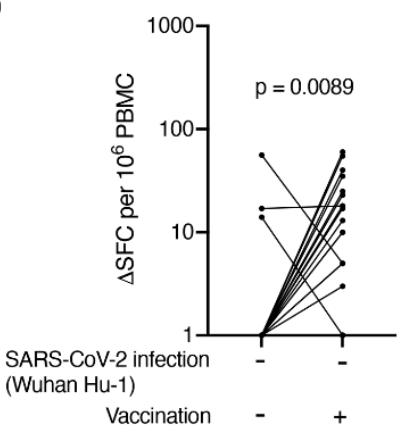

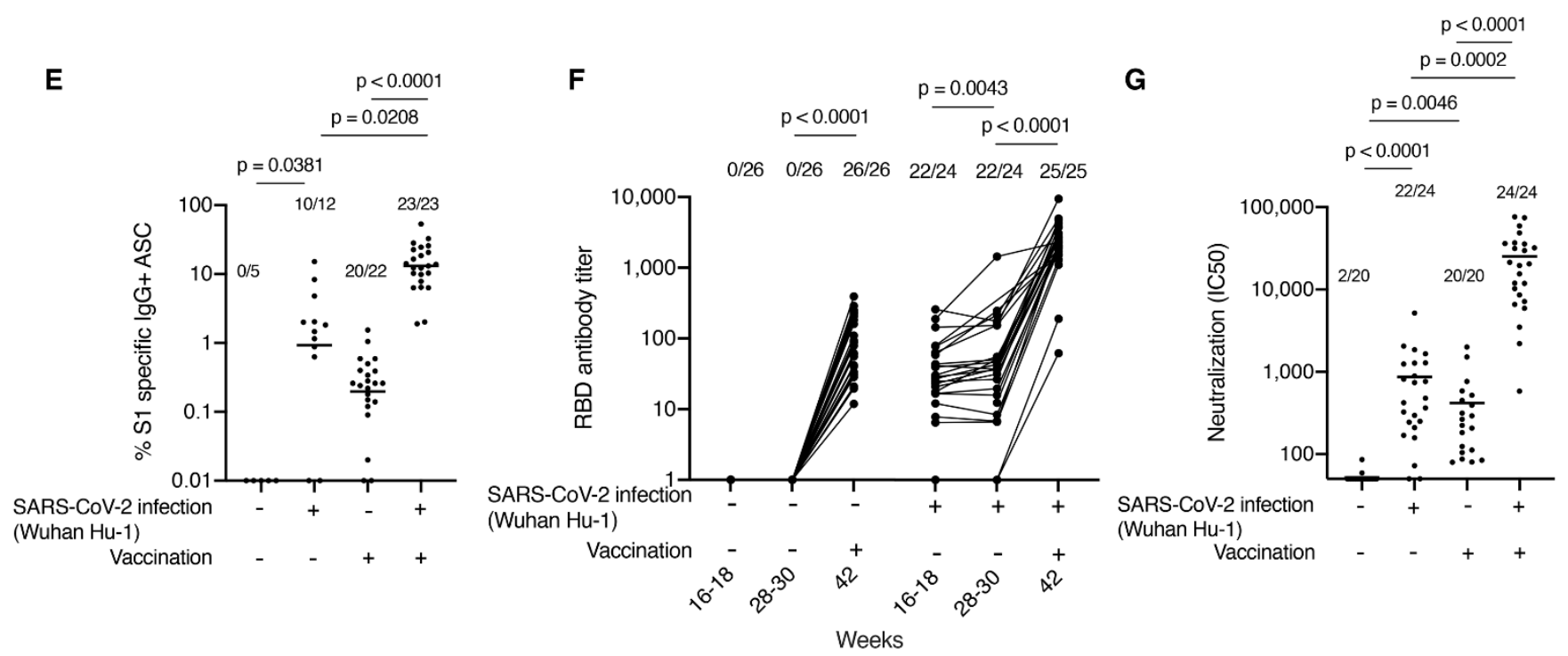

H

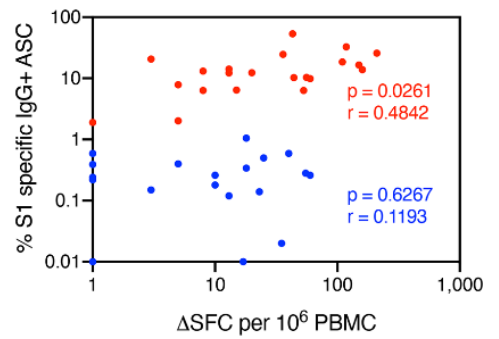

I

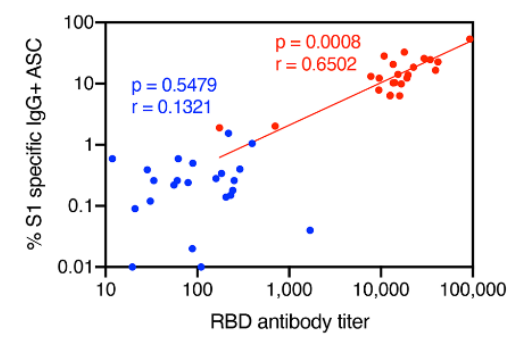


Fig. 1. Impact of prior natural infection with SARS-CoV-2 during the first wave on $T$ and $B$ cell responses to a single dose of the mRNA COVID-19 vaccine, BNT162b2. (A) N Ab measured by electrochemiluminescence immunoassay analyzer (ECLIA) in serum samples from HCW with $(n=25)$ and without $(n=26)$ laboratory confirmed SARS-CoV-2 infection (Wuhan Hu-1, during the first wave) 3 weeks after a single dose of the mRNA COVID-19 vaccine, BNT162b2. (B) Magnitude of T cell response to spike protein and spike mapped epitope peptides (MEP) in HCW with and without laboratory confirmed SARS-CoV-2 infection ( $\mathrm{n}=23$ per group). Data are shown pre-vaccination (16-18 weeks after infection) and 3 weeks after the first dose vaccination (week 42) with line at geo mean. (C) Proportion of HCW with $(n=23)$ and without $(n=23)$ laboratory confirmed SARSCoV-2 infection (during the first wave) with a T cell response to Spike protein within the range (0, 1-19, 20-79, $>80 \triangle \mathrm{SFC} / 10^{6} \mathrm{PBMC}$ ) before and 3 weeks after first dose vaccination. (D) Magnitude of $\mathrm{T}$ cell response to spike protein in HCW without a history of SARS-CoV-2 infection, plotted pairwise at 16-18 weeks and 42 weeks (3 weeks after first dose vaccination). (E) Percentage of $\mathrm{S} 1$ specific $\operatorname{lgG}^{+}$antibody secreting cells (ASC) in vaccinated HCW with $(n=23)$ and without $(n=22)$ prior SARS-CoV-2 infection and in unvaccinated HCW with $(n=12)$ and without prior infection $(n=5)$. Line at geo mean. $(F)$ RBD Ab titers measured by ECLIA in serum samples from HCW with $(n=25)$ and without $(n=26)$ laboratory confirmed SARS-CoV-2 infection following first dose vaccination. (G) Neutralizing antibody titer (IC50) against Wuhan Hu-1 authentic virus in HCW with ( $\mathrm{H}=$ 24) and without $(n=20)$ laboratory confirmed SARS-CoV-2 infection. Line at arithmetic mean. $(H)$ Correlation between percentage of S1 specific ASC and magnitude of T cell response to spike protein in vaccinated HCW with ( $n=21$, red) and without ( $n=19$, blue) a history of SARS-CoV-2 infection during the first wave. (I) Correlation between percentage of S1 specific ASC and RBD Ab titer in HCW with $(n=23$, red) and without $(n=23$, blue) a history of SARS-CoV-2 infection. [(A), (B), (E), and (F)] Numbers of HCW in each group with detectable responses are shown. $[(F)$ and $(G)]$ Data are shown pre-vaccination (16-18 weeks after infection) and 3 weeks after the first dose vaccination (week 42). [(A), (D), and (F)] Wilcoxon matched-pairs signed rank test. [(B), (C), $(E)$, and $(G)]$ Kruskal Wallis multiple comparison ANOVA with Dunn's correction. $[(H)$ and $(I)]$ Spearman's rank correlation. Ab, antibody; HCW, health care workers; RBD, receptor binding domain; S1, spike subunit 1; SFC, spot forming cells. 

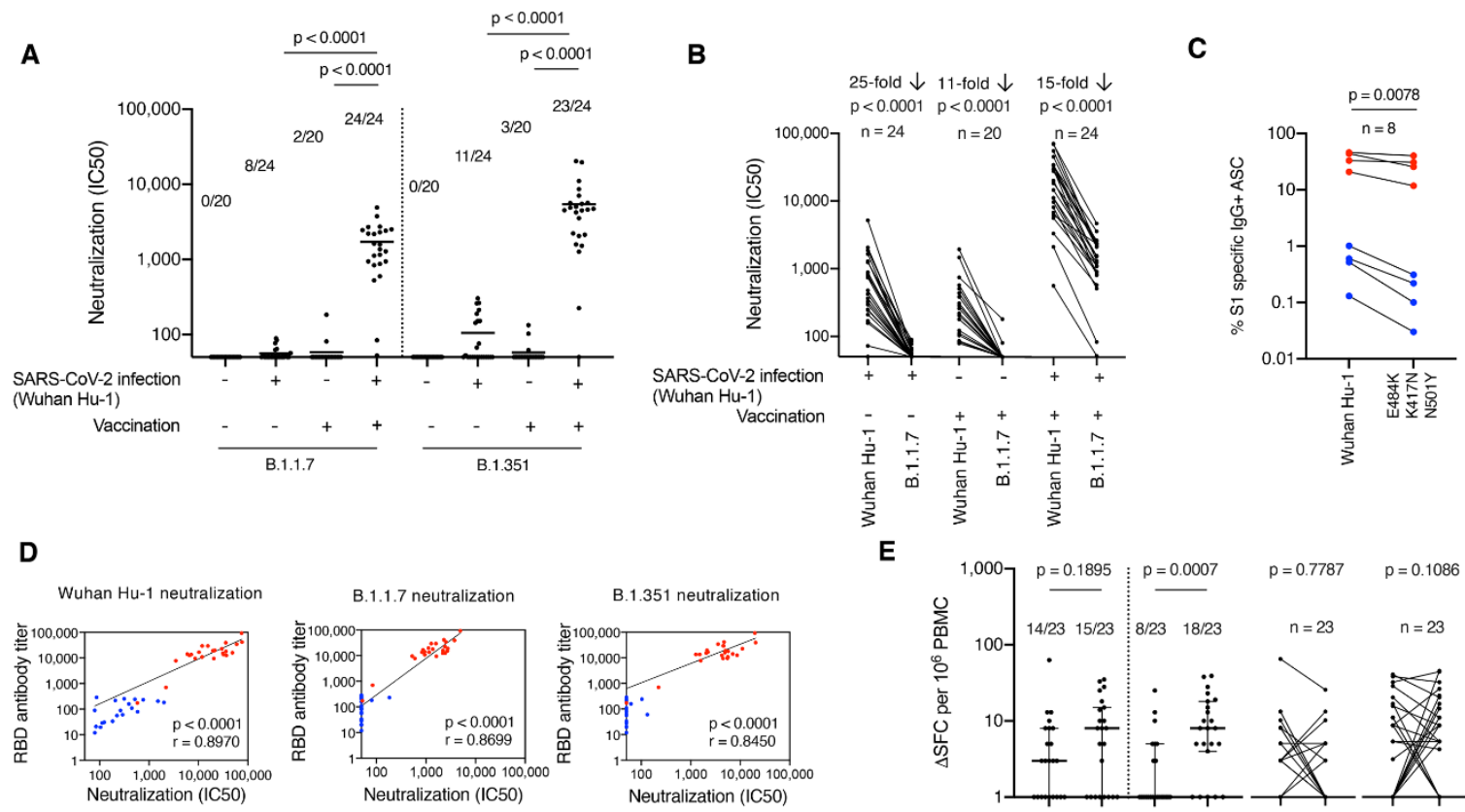

E
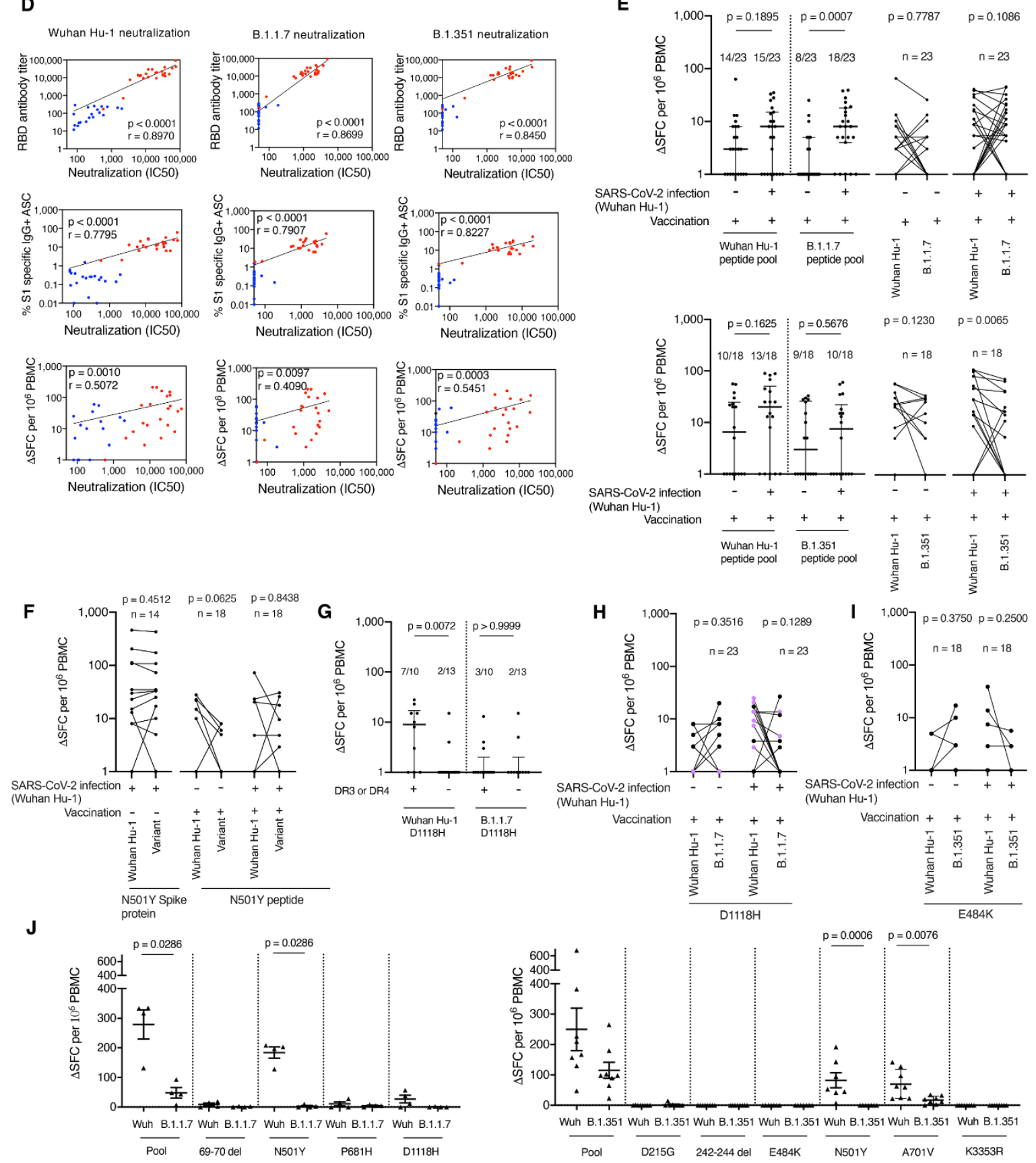
Fig. 2. Impact of vaccination and prior natural infection with SARS-CoV-2 during the first wave on T and B cell responses to the UK B.1.1.7 and South African B.1.315 variants. (A) Neutralizing antibody ( $\mathrm{nAb}$ ) titer (IC50) against B.1.1.7 and B.1.351 authentic virus in HCW with $(n=24)$ and without $(n=20)$ laboratory confirmed SARS-CoV-2 infection (Wuhan Hu-1). Lines at arithmetic mean. Data are shown pre-vaccination (16-18 weeks after infection) and 3 weeks after the first dose vaccination (week 42). (B) nAb (IC50) titers against Wuhan $\mathrm{Hu}-1$ and B.1.1.7 authentic viruses plotted pairwise by individual. (C) Percentage of Wuhan Hu-1 S1 and S1 containing variant mutations (E484K, K417N and N501Y) specific IgG ${ }^{+}$antibody secreting cells (ASC) in vaccinated $\mathrm{HCW}$ with $(n=4)$ and without $(n=4)$ prior SARS-CoV-2 infection. (D) Correlations between $n A b$ (IC50) titers of Wuhan Hu-1, B.1.1.7 or B.1.351 authentic virus and RBD Ab titer, percentage of S1 specific ASC and magnitude of T cell response to S1 protein in vaccinated HCW with ( $n=22-24$, red) and without ( $n=18-20$, blue) a history of SARS-CoV-2 infection. (E) Magnitude of $T$ cell response to Wuhan Hu-1, B.1.1.7 or B.1.351 peptide pools in vaccinated HCW with $(n=23$ or 18$)$ and without ( $n=23$ or 18 ) SARS-CoV-2 infection (Wuhan Hu-1), plotted as grouped data (median plus interquartile range) and pairwise for each individual. ( $F$ ) Magnitude of T cell response to Wuhan $\mathrm{Hu}-1 \mathrm{~S} 1$ protein and N501Y variant spike RBD protein in unvaccinated HCW with laboratory confirmed SARS-CoV-2 infection $(n=14)$ or to Wuhan Hu-1 and N501Y mutated peptide in vaccinated HCW with $(n=18)$ and without $(n=18)$ a history of SARS-CoV-2 infection, plotted pairwise by individual. (G) Magnitude of T cell response to Wuhan Hu-1 or B.1.1.7 D1118H peptide in vaccinated HCW with a history of SARS-CoV-2 infection $(n=23)$, plotted by $\mathrm{DRB1}^{*} 0301 / \mathrm{DRB1}{ }^{*} 0401$ status. Lines at median plus interquartile range. $(\mathrm{H})$ Magnitude of $\mathrm{T}$ cell response to Wuhan Hu-1 or B.1.1.7 D1118H peptide in vaccinated $\mathrm{HCW}$ with $(\mathrm{n}=23)$ and without ( $\mathrm{n}$ = 23) a history of SARS-CoV-2 infection plotted pairwise by individual and with individuals carrying DRB1*0301 or DRB1*0401 alleles marked in purple. (I) Magnitude of T cell response to Wuhan Hu1 or B.1.351 E484K mutated peptide in vaccinated HCW with $(n=18)$ and without $(n=18)$ a history of SARS-CoV-2 infection, plotted pairwise by individual. $(\mathrm{J}$ ) Magnitude of T cell response to Wuhan Hu-1 (Wuh), B.1.1.7 or B.1.315 peptide pools and individual peptides in Wuhan Hu-1 peptide immunized HLA-DRB1 ${ }^{*} 04: 01$ transgenic mice (left-hand panel $n=4$, right-hand panel $n=8$. Lines at arithmetic mean + SEM). (A) Kruskal Wallis multiple comparison ANOVA with Dunn's correction. $[(B),(C),(E)$ - right-hand panels, $(F),(H)$, and $(I)]$ Wilcoxon matched-pairs signed rank test. (D) Spearman's rank correlation. [(E) - left-hand panels, $(G)$, and $(J)]$ Mann-Whitney U test. ASC, antibody secreting cells; HCW, health care workers; RBD, receptor binding domain; S1, spike subunit 1; SFC, spot forming cells. 


\section{Science}

Prior SARS-CoV-2 infection rescues $B$ and $T$ cell responses to variants after first vaccine dose

Catherine J. Reynolds, Corinna Pade, Joseph M. Gibbons, David K. Butler, Ashley D. Otter, Katia Menacho, Marianna Fontana, Angelique Smit, Jane E. Sackville-West, Teresa Cutino-Moguel, Mala K. Maini, Benjamin Chain, Mahdad Noursadeghi, UK COVIDsortium Immune Correlates Network, Tim Brooks, Amanda Semper, Charlotte Manisty, Thomas A. Treibel, James C. Moon, UK COVIDsortium Investigators, Ana M. Valdes, Áine McKnight, Daniel M. Altmann and Rosemary Boyton

published online April 30, 2021

ARTICLE TOOLS

SUPPLEMENTARY MATERIALS

RELATED
CONTENT

REFERENCES

PERMISSIONS http://science.sciencemag.org/content/early/2021/04/29/science.abh1282

http://science.sciencemag.org/content/suppl/2021/04/29/science.abh1282.DC1

http://stm.sciencemag.org/content/scitransmed/13/590/eabf7517.full http://stm.sciencemag.org/content/scitransmed/13/578/eabd6990.full http://stm.sciencemag.org/content/scitransmed/13/577/eabd2223.full http://stm.sciencemag.org/content/scitransmed/13/577/eabf1555.full

This article cites 25 articles, 5 of which you can access for free http://science.sciencemag.org/content/early/2021/04/29/science.abh1282\#BIBL

http://www.sciencemag.org/help/reprints-and-permissions

Use of this article is subject to the Terms of Service

Science (print ISSN 0036-8075; online ISSN 1095-9203) is published by the American Association for the Advancement of Science, 1200 New York Avenue NW, Washington, DC 20005. The title Science is a registered trademark of AAAS.

Copyright (C) 2021 The Authors, some rights reserved; exclusive licensee American Association for the Advancement of Science. No claim to original U.S. Government Works. Distributed under a Creative Commons Attribution License 4.0 (CC BY). 